\title{
Computation of Pump-Leak Flux Balance in Animal Cells
}

\author{
Igor A. Vereninov ${ }^{a} \quad$ Valentina E. Yurinskaya ${ }^{b} \quad$ Michael A. Model $^{c} \quad$ Florian Lang $^{d}$ \\ Alexey A. Vereninov
}

\begin{abstract}
aSt-Petersburg State Polytechnical University, St-Petersburg, Russia, 'Laboratory of Cell Physiology, Institute of Cytology, Russian Academy of Sciences, St-Petersburg, Russia, 'Department of Biological Sciences, Kent State University, Kent, Ohio, USA, dDepartment of Physiology, University of Tübingen, Germany
\end{abstract}

\section{Key Words}

Cell ion balance $\cdot$ Cell water balance $\cdot$ Ion transport $\cdot$ Sodium pump $\bullet$ Cotransport $\bullet$ Channels - Ion fluxes

\begin{abstract}
Background/Aims: Many vital processes in animal cells depend on monovalent ion transport across the plasma membrane via specific pathways. Their operation is described by a set of nonlinear and transcendental equations that cannot be solved analytically. Previous computations had been optimized for certain cell types and included parameters whose experimental determination can be challenging. Methods: We have developed a simpler and a more universal computational approach by using fewer kinetic parameters derived from the data related to cell balanced state. A file is provided for calculating unidirectional $\mathrm{Na}^{+}, \mathrm{K}^{+}$, and $\mathrm{Cl}^{-}$fluxes via all major pathways (i.e. the $\mathrm{Na} / \mathrm{K}$ pump, $\mathrm{Na}^{+}, \mathrm{K}^{+}, \mathrm{Cl}^{-}$channels, and $\mathrm{NKCC}, \mathrm{KC}$ and NC cotransporters) under a balanced state and during transient processes. Results: The data on the $\mathrm{Na}^{+}, \mathrm{K}^{+}$, and $\mathrm{Cl}^{-}$distribution and the pump flux of $\mathrm{K}^{+}\left(\mathrm{Rb}^{+}\right)$are obtained on $\mathrm{U} 937$ cells before and after inhibiting the pump with ouabain. There was a good match between the results of calculations and the experimentally measured dynamics of ion redistribution caused by blocking the pump. Conclusion: The presented approach can serve as an effective tool for analyzing monovalent ion transport in the whole cell, determination of the rate coefficients for ion transfer via major pathways and studying their alteration under various conditions.
\end{abstract}

Copyright $(2014$ S. Karger AG, Basel

\section{Introduction}

Electrochemical gradients of monovalent ions across the plasma membrane are indispensable for normal functioning of any cell. They are determined by charged osmotically active material sequestered in the cell and by the active and passive transport of ions mediated 
by various carriers and channels. The overall ion traffic is described by a set of nonlinear and transcendental equations, which cannot be solved analytically. Numerical solutions of this problem have been developed in a series of studies [1-10]. Some of the published codes and executable files are available in a form that allows modification of kinetic parameters to some extent $[7,10]$. Nevertheless, further study in this direction seems to be necessary because the reported detailed computations have been optimized only for certain cell types, such as human red blood cells and reticulocytes [3,10], guinea-pig cardiomyocytes [7], or frog skeletal muscle $[4,8]$. However, erythrocytes and muscle cells are characterized by rather extreme values of membrane potential (MP), on the order of $-10 \mathrm{mV}$ and $-90 \mathrm{mV}$, respectively. For our study we chose the proliferating human lymphoid U937 cell line, which better represents the typical animal cell owing to its faster metabolism and intermediate $(-40 \div-60 \mathrm{mV}) \mathrm{MP}$. The monovalent ion flux balance in U937 cells has been comprehensively characterized in our laboratory [11-14]. In the present paper we have developed an improved computational model which, compared to the previous models, uses phenomenological parameters derived from the balanced state. We show how the $\mathrm{Na} / \mathrm{K}$ pump, $\mathrm{Na}^{+}, \mathrm{K}^{+}, \mathrm{Cl}^{-}$ion channels, and the three major types of cotransporters, $\mathrm{Na}^{+}-\mathrm{K}^{+}-2 \mathrm{Cl}^{-}$(NKCC), $\mathrm{K}^{+}-\mathrm{Cl}^{-}$(KC) and $\mathrm{Na}^{+}-\mathrm{Cl}^{-}$(NC), should affect ion fluxes and MP in cells of different types, i.e. high-potassium cells with high MP (excitable nerve and skeletal muscle cells), high-potassium cells with low MP (human erythrocytes), and low-potassium cells with low MP (erythrocytes of some carnivores and ruminants). Due to a large number of variables it is impossible to demonstrate all possible outcomes. Therefore, we present an executable file which allows modeling of the behavior of any cell type either under conditions of balanced transmembrane ion distribution or during transition processes caused by alteration of ion pathways and/or of the cell environment. For input parameters, we use intracellular $[\mathrm{Na}]_{\mathrm{i}^{\prime}}[\mathrm{K}]_{\mathrm{i}},[\mathrm{Cl}]_{\mathrm{i}}$ concentrations and $\mathrm{Rb}^{+}$ouabaininhibitable and -resistant influxes, which are assumed to be known from the experiment. It was found that modeling based on parameters derived from balanced ion distribution achieves quantitatively accurate description of transient processes caused by blocking the pump with ouabain. We consider this outcome as an indication that our mathematical model is well suited to describe real cellular processes.

\section{Materials and Methods}

Human histiocytic lymphoma U937 cells were obtained from the Russian Cell Culture Collection (cat. number 160B2). The cells were maintained in RPMI 1640 medium (Biolot, Russia) with 10\% fetal calf serum (HyClone, Standard, United State) at $37^{\circ} \mathrm{C}$ and $5 \% \mathrm{CO}_{2}$. Ouabain was purchased from SigmaAldrich (Steinheim, Germany). Percoll was from Pharmacia (Sweden). The isotope ${ }^{36} \mathrm{Cl}^{-}$was from Isotope (Russia). Salts were of analytical grade and were from Reachem (Russia). The experimental methods used in this work have been described in detail earlier [11-15]. Briefly, intracellular $\mathrm{K}^{+}, \mathrm{Na}^{+}$and $\mathrm{Rb}^{+}$content was analyzed by flame emission spectrometry, $\mathrm{Cl}^{-}$content was measured using ${ }^{36} \mathrm{Cl}^{-}$isotope. $\mathrm{Rb}^{+}$influx via $\mathrm{Na}^{+}$/ $\mathrm{K}^{+}$pump was evaluated from the difference between $\mathrm{Rb}^{+}$uptake in the presence and absence of $0.1 \mathrm{mM}$ ouabain. The water content was evaluated by cell buoyant density in Percoll density gradient. The results were statistically treated using Student t-test.

\section{Results}

Equations

The mandatory conditions of macroscopic electroneutrality and osmotic balance can be written as $[6,9]$ :

$$
\begin{aligned}
& {[\mathrm{Na}]_{i}+[\mathrm{K}]_{i}-[\mathrm{Cl}]_{i}+\frac{z A}{V}=0} \\
& {[\mathrm{Na}]_{o}+[\mathrm{K}]_{o}+[\mathrm{Cl}]_{o}+[\mathrm{B}]_{o}=[\mathrm{Na}]_{i}+[\mathrm{K}]_{i}+[\mathrm{Cl}]_{i}+\frac{A}{V}}
\end{aligned}
$$


The subscripts $i$ and $o$ indicate the intracellular and extracellular concentrations in $\mathrm{mM}$, respectively; $V$ is the volume occupied by intracellular water $(\mathrm{ml})$, which is assumed to be approximately equal to the cell volume; $A$ is the total amount (in mmol) of membraneimpermeant osmolytes with mean valence $z ;[B]_{o}$ is the external concentration of the membrane-impermeant solute (see Table 1 for symbols and definitions).

From Eqs. 1, 2 it follows that

$$
\begin{aligned}
& z=\left([\mathrm{Cl}]_{i}-[\mathrm{Na}]_{i}-[\mathrm{K}]_{i}\right) /\left([\mathrm{Na}]_{o}+[\mathrm{K}]_{o}+[\mathrm{Cl}]_{o}+[\mathrm{B}]_{o}-[\mathrm{Cl}]_{i}-[\mathrm{Na}]_{i}-[\mathrm{K}]_{i}\right) \\
& V / A=1 /\left([\mathrm{Na}]_{o}+[\mathrm{K}]_{o}+[\mathrm{Cl}]_{o}+[\mathrm{B}]_{o}-[\mathrm{Cl}]_{i}-[\mathrm{Na}]_{i}-[\mathrm{K}]_{i}\right) \\
& V=z A /\left([\mathrm{Cl}]_{i}-[\mathrm{Na}]_{i}-[\mathrm{K}]_{i}\right)
\end{aligned}
$$

Dependences of ion fluxes via electroconductive channels and NKCC, KC, NC cotransporters on the ion concentration gradients and MP were formulated in the traditional way $[3,7-10]$. The equation for $\mathrm{Na}^{+}$and $\mathrm{K}^{+}$fluxes via the pump was used in a simple linear form [1].

To express the fluxes, the following equations were used:

$$
\begin{gathered}
\frac{d\left([\mathrm{Na}]_{i} V\right)}{d t}=V\left\{\left(p_{N a} u\left([\mathrm{Na}]_{i} \exp (u)-[\mathrm{Na}]_{o}\right) / g-\beta[N a]_{i}+J_{N C}+J_{N K C C}\right\}\right. \\
\frac{d\left([K]_{i} V\right)}{d t}=V\left\{\left(p_{K} u\left([K]_{i} \exp (u)-[K]_{o}\right) / g+\beta[N a]_{i} / \gamma+J_{N K C C}+J_{K C}\right\}\right. \\
\frac{d\left([\mathrm{Cl}]_{i} V\right)}{d t}=V\left\{\left(p_{C l} u\left([C l]_{o} \exp (u)-[C l]_{i}\right) / g+J_{N C}+J_{K C}+2 J_{N K C C}\right\}\right.
\end{gathered}
$$

Here $u$ is the dimensionless MP related to absolute values $U(\mathrm{mV})$ as $U=u \mathrm{RT} / \mathrm{F}=26.7 u$ for $37^{\circ} \mathrm{C}$ and $g=1-\exp (u)$

The left-hand sides of Eqs. 6-8 represent the rates of change in the cell ion content. The right-hand sides express fluxes via channels, the Na/K pump, and cotransporters. The rate coefficients $p_{\mathrm{Na}^{\prime}} p_{\mathrm{K}^{\prime}} p_{\mathrm{Cl}}$ characterizing channel ion transfer are similar to the Goldman's coefficients. Fluxes $J_{\mathrm{NC}} J_{\mathrm{KC}} J_{\mathrm{NKCC}}$ are related to internal and external ion concentrations as

$$
\begin{aligned}
& J_{N C}=i_{N C}\left([\mathrm{Na}]_{o}[\mathrm{Cl}]_{o}-[\mathrm{Na}]_{i}[\mathrm{Cl}]_{i}\right) \\
& J_{K C}=i_{K C}\left([\mathrm{~K}]_{o}[\mathrm{Cl}]_{o}-[\mathrm{K}]_{i}[\mathrm{Cl}]_{i}\right) \\
& J_{N K C C}=i_{N K C C}\left([\mathrm{Na}]_{o}[\mathrm{~K}]_{o}[\mathrm{Cl}]_{o}[\mathrm{Cl}]_{o}-[\mathrm{Na}]_{i}[\mathrm{~K}]_{i}[\mathrm{Cl}]_{i}[\mathrm{Cl}]_{i}\right)
\end{aligned}
$$

Here $i_{\mathrm{NC}}, i_{\mathrm{KC}}$, and $i_{\mathrm{NKCC}}$ are the rate coefficients for cotransporters.

By multiplying Eq. 1 by $V$ and taking a time derivative, we obtain the following relationship:

$$
\frac{d\left([N a]_{i} V\right)}{d t}+\frac{d\left([K]_{i} V\right)}{d t}-\frac{d\left([C l]_{i} V\right)}{d t}=0
$$

From Eqs. 6-8 and taking Eq. 10 into account, a transcendental equation for the potential $u$ follows:

$$
F(u)=\exp (u)-\frac{p_{N a}[N a]_{o}+p_{K}[K]_{o}+p_{C l}[C l]_{i}+\beta[N a]_{i}(1-1 / \gamma) / u}{p_{N a}[N a]_{i}+p_{K}[K]_{i}+p_{C l}[C l]_{o}+\beta[N a]_{i}(1-1 / \gamma) / u}=0
$$




\section{Algorithm}

Modeling of the flux balance in a cell requires a numerical solution of a Cauchy problem for the set of Eqs. 6-8 [16]. The values of $z$ and $V$ compatible with the conditions of electroneutrality and osmotic balance have to be computed at the outset. Cell volume $V$ and potential $u$ are found at every step of numerical integration. The transcendental Eq. 11 is solved in two stages. First, one finds the values of $u$ that ensure that $F(u)$ crosses zero

Table 1. Symbols and definitions

\begin{tabular}{|c|c|c|c|}
\hline Definitions & $\begin{array}{l}\text { In text, Figures and } \\
\text { Equations }\end{array}$ & $\begin{array}{l}\text { In files } \\
\text { DATA.txt, } \\
\text { RES.txt }\end{array}$ & Units \\
\hline Ion species & $\mathrm{Na}^{+}, \mathrm{K}^{+}, \mathrm{Cl}^{-}, \mathrm{Rb}^{+}$ & $\mathrm{Na}, \mathrm{K}, \mathrm{Cl}$ & \\
\hline Types of cotransport & NC, NKCC, KC & & \\
\hline $\begin{array}{l}\text { Concentration of ions in cell water or external } \\
\text { medium }\end{array}$ & $\begin{array}{l}{[\mathrm{Na}]_{\mathrm{i}},[\mathrm{K}]_{\mathrm{i}},[\mathrm{Cl}]_{\mathrm{i}}} \\
{[\mathrm{Na}]_{\mathrm{o}},[\mathrm{K}]_{\mathrm{o}},[\mathrm{Cl}]_{\mathrm{o}}}\end{array}$ & $\begin{array}{l}\text { na, } k, c l, n a 0, k 0 \\
\text { clo }\end{array}$ & $\mathrm{mM}$ \\
\hline $\begin{array}{l}\text { External concentration of membrane- } \\
\text { impermeant osmolytes }\end{array}$ & {$[\mathrm{B}]_{\mathrm{o}}$} & $B O$ & $\mathrm{mM}$ \\
\hline $\begin{array}{l}\text { Intracellular content of membrane- } \\
\text { impermeant osmolytes }\end{array}$ & $A$ & & $\begin{array}{l}\text { mmol, may be related to } \mathrm{g} \text { cell } \\
\text { protein or cell number etc. }\end{array}$ \\
\hline Cell water volume & $V$ & & $\begin{array}{l}\mathrm{ml} \text {, may be related to g cell } \\
\text { protein or cell number etc. }\end{array}$ \\
\hline $\begin{array}{l}\text { Membrane-impermeant osmolyte } \\
\text { concentration in cell water }\end{array}$ & $A / V$ & $A / V$ & $\mathrm{mM}$ \\
\hline Cell water content per unit of $A$ & $V / A$ & $V / A$ & $\mathrm{ml} \cdot \mathrm{mmol}^{-1}$ \\
\hline $\begin{array}{l}\text { Mean valence of membrane-impermeant } \\
\text { osmolytes, } A\end{array}$ & $z$ & $z$ & dimensionless \\
\hline Permeability coefficients & $p_{\mathrm{Na}}, p_{\mathrm{K}}, p_{\mathrm{Cl}}$ & $p n a, p k, p c l$ & $\min ^{-1}$ \\
\hline Pump rate coefficient & $\beta$ & beta & $\min ^{-1}$ \\
\hline $\mathrm{Na} / \mathrm{K}$ pump fluxes stoichiometry & $\gamma$ & gamma & dimensionless \\
\hline Membrane potential, MP & $U$ & $U$ & $\mathrm{mV}$ \\
\hline Dimensionless membrane potential & $u, \quad U=u \mathrm{RT} / \mathrm{F}$ & $u$ & dimensionless \\
\hline $\begin{array}{l}\text { Net fluxes mediated by cotransport NC, KC, } \\
\text { NKCC }\end{array}$ & $J_{\mathrm{NC}}, J_{\mathrm{NKCC}}, J_{\mathrm{KC}}$ & $\begin{array}{l}\text { NetNC, NetKC, } \\
\text { NetNKCC }\end{array}$ & $\mu \mathrm{mol} \cdot \mathrm{min}^{-1} \cdot(\mathrm{ml} \text { cell water })^{-1}$ \\
\hline $\mathrm{Na}$ efflux via the pump & $-\beta[\mathrm{Na}]_{\mathrm{i}}$ & $P U M P(\mathrm{Na})$ & $\mu \mathrm{mol} \cdot \mathrm{min}^{-1} \cdot(\mathrm{ml} \text { cell water })^{-1}$ \\
\hline K influx via the pump & $\beta[\mathrm{Na}]_{\mathrm{i}} / \gamma$ & $P U M P(\mathrm{~K})$ & $\mu \mathrm{mol} \cdot \mathrm{min}^{-1} \cdot(\mathrm{ml} \text { cell water })^{-1}$ \\
\hline Net fluxes mediated by channels & & NetCh & $\mu \mathrm{mol} \cdot \mathrm{min}^{-1} \cdot(\mathrm{ml} \text { cell water })^{-1}$ \\
\hline $\begin{array}{l}\text { Unidirectional influxes of } \mathrm{Na}, \mathrm{K} \text { or } \mathrm{Cl} \text { via } \\
\text { channels, or cotransporters } \mathrm{NC}, \mathrm{KC} \text { or NKCC }\end{array}$ & & $\begin{array}{l}\operatorname{In} C h, \operatorname{In} N C \\
\operatorname{In} K C, \operatorname{In} N K C C\end{array}$ & $\mu \mathrm{mol} \cdot \mathrm{min}^{-1} \cdot(\mathrm{ml} \text { cell water })^{-1}$ \\
\hline Time derivatives of concentrations & & prna, prk, prcl & $\mathrm{mM} \cdot \mathrm{min}^{-1}$ \\
\hline Cotransport rate coefficients & $i_{\mathrm{NC}}, i_{\mathrm{KC}}$ & inc, $i k c$, & $\mathrm{ml} \cdot \mu \mathrm{mol}^{-1} \cdot \mathrm{min}^{-1}$ \\
\hline $\begin{array}{l}\text { "Old" and "new" external concentration of all } \\
\text { osmolytes at anisosmotic shift }\end{array}$ & $\begin{array}{l}i_{\mathrm{NKCC}} \\
S_{O O}, S_{O N}\end{array}$ & inkcc & $\begin{array}{l}\mathrm{ml}^{3} \cdot \mu \mathrm{mol}^{-3} \cdot \mathrm{min}^{-1} \\
\mathrm{mM}\end{array}$ \\
\hline $\mathrm{S}_{\mathrm{oN}} / \mathrm{S}_{\mathrm{oo}}$ ratio & $k v$ & $k v$ & dimensionless \\
\hline $\begin{array}{l}\text { Number of time points between output of } \\
\text { results }\end{array}$ & & $h p$ & dimensionless \\
\hline $\begin{array}{l}\text { Transmembrane electrochemical potential } \\
\text { difference for } \mathrm{Na}^{+}, \mathrm{K}^{+} \text {, and } \mathrm{Cl}^{-}\end{array}$ & $\Delta \mu_{\mathrm{Na}}, \Delta \mu_{\mathrm{K}}, \Delta \mu_{\mathrm{Cl}}$ & mun, muk, mucl & $\mathrm{mV}$ \\
\hline $\begin{array}{l}\text { Ratio of ouabain-sensitive to ouabain-resistant } \\
\mathrm{Rb}^{+}\left(\mathrm{K}^{+}\right) \text {influx }\end{array}$ & OSOR & OSOR & dimensionless \\
\hline
\end{tabular}

at physically meaningful values of $u$. Next, the process of root refining ZEROIN from the calculation package FMM [17] is applied. Numerical solution of Eqs. 6-8 was accomplished by the explicit Euler method. To monitor the approach to stationary state, time derivatives of sodium, potassium and chloride concentrations are displayed.

This system of equations does not have a physically meaningful solution for every value of parameters or initial concentrations. This was taken into account in program development, and the following diagnostic tools were provided to assist the user:

1. In studying the dependence of the process on external ion concentrations, one enters new concentrations along with parameter $k v=\mathrm{S}_{o N} / \mathrm{S}_{o 0^{\prime}}$ where the second subscripts stand for the old $(\mathrm{O})$ and new $(\mathrm{N})$ values.

$$
\begin{aligned}
& \mathrm{S}_{o O}=[\mathrm{Na}]_{o O}+[\mathrm{K}]_{o O}+[\mathrm{Cl}]_{o O}+[\mathrm{B}]_{o O} \\
& \mathrm{~S}_{o N}=[\mathrm{Na}]_{o N}+[\mathrm{K}]_{o N}+[\mathrm{Cl}]_{o N}+[\mathrm{B}]_{o N}
\end{aligned}
$$

If the parameter $k v$ or the initial concentrations do not meet the requirements of electric or osmotic equilibrium, a message "BAD INITIAL DATA" is generated.

2. If the program fails to compute the dimensionless potential $u$ in the physically justified range (which may happen if one enters unrealistic parameters or initial concentrations) the program reports an error, "RANGE NOT FOUND". 
Table 2. The layout of the file DATA.txt. The parameters $n a 0, k 0, c l 0$ and $B 0$ are extracellular concentrations $(\mathrm{mM}) ; n a, k$ and $c l$ are intracellular concentrations; $k v$ is the ratio of the initial external to internal osmolarity; beta is the pump rate coefficient $\left(\mathrm{min}^{-1}\right)$; gamma is the pump $\mathrm{Na} / \mathrm{K}$ stoichiometric coefficient; $p n a, p k$, pcl are channel permeability coefficients $\left(\mathrm{min}^{-1}\right)$; inc, ikc, inkcc are the rate coefficients for the NC, KC cotransporters $\left(\mathrm{ml} \cdot \mathrm{umol}^{-1} \cdot \mathrm{min}^{-1}\right)$ and for cotransporter NKCC $\left(\mathrm{ml}^{3} \cdot \mathrm{mmol}^{-3} \cdot \mathrm{min}^{-1}\right)$. The parameter $h p$ determines the number of integration steps between data output. If one wishes to follow the initial stages of the process, $h p$ should be made small (5-50), and if the process is slow and one is interested in the balanced state, $h p$ can be increased to $1000-5000$

\begin{tabular}{lllllllllllllllll}
\hline naO & $k 0$ & clo & BO & $k v$ & $n a$ & $k$ & $c l$ & beta & gamma & pna & $p k$ & $p c l$ & inc & ikc & inkcc & hp \\
\hline 140 & 5.8 & 116 & 48.2 & 1 & 58 & 136 & 63 & 0.039 & 1.5 & 0.00317 & 0.023 & 0.00354 & 0.00003 & 0.0 & 0.0 & 250
\end{tabular}

Table 3. Transition of the system to the balanced state as displayed in the file RES.txt: The values typical of U937 cells were chosen for this example of transition to the balanced state. In addition to the initial parameters already contained in Table 1, the parameters and variables here include the following: current intracellular ion concentrations $n a, k, c l(\mathrm{mM})$; membrane potential $U(\mathrm{mV})$; cell water content $V / A(\mathrm{ml}$ per mmol of $A$ ); transmembrane electrochemical potential differences, mun, muk, mucl $(\mathrm{mV}) \mathrm{for} \mathrm{Na}^{+}, \mathrm{K}^{+}$, and $\mathrm{Cl}^{-}$, respectively, calculated as mun $\left.=26.7 * \ln (n a / n a 0)+U, m u k=26.7^{*} \ln (k / k 0)+U, m u c l=26.7 * \ln (\mathrm{cl} / \mathrm{cl} 0)-U\right)$; derivatives prna, prk, prcl, characterizing the rate of change in $[\mathrm{Na}]_{\mathrm{i}},[\mathrm{K}]_{\mathrm{i}}$ and $[\mathrm{Cl}]_{\mathrm{i}}$; net fluxes of $\mathrm{Na}^{+}, \mathrm{K}^{+}$, and $\mathrm{Cl}^{-}$via separate ion pathways $\left(\mu \mathrm{mol} \cdot \mathrm{ml}^{-1} \cdot \mathrm{min}^{-1}\right) ; A / V(\mathrm{mM})$ and the mean valence of membrane-impermeant intracellular osmolytes, $z$. The displayed values of fluxes, as well as OSOR, the ratio of ouabain-sensitive to ouabain-resistant $\mathrm{K}^{+}$influx, are calculated only in the bottom line, i.e. for the latest time point. The fluxes at any time can be found by varying $h p$. The values of fluxes per $g$ of cell protein can be found by multiplying the displayed values by cell water content per $\mathrm{g}$ of cell protein, which is close to $6.5 \mathrm{ml} \cdot \mathrm{g}^{-1}$ in U937 cells under normal conditions

\begin{tabular}{|c|c|c|c|c|c|c|c|c|c|c|c|}
\hline$t$ & $U$ & $n a$ & $k$ & $\mathrm{cl}$ & $V / A$ & mun & $m u k$ & mucl & prna & $p r k$ & prcl \\
\hline 0 & -54.7 & 58 & 136 & 63 & 18.87 & -78.2 & 29.5 & 38.4 & 0 & 0 & 0 \\
\hline 25 & -52.9 & 43.8 & 150.2 & 63.1 & 18.88 & -83.9 & 34 & 36.6 & -0.3353 & 0.3299 & 0.0129 \\
\hline 50 & -52.1 & 38.5 & 155.3 & 63.5 & 18.97 & -86.6 & 35.6 & 36.1 & -0.1249 & 0.1162 & 0.0206 \\
\hline 75 & -51.8 & 36.5 & 157.1 & 64 & 19.08 & -87.7 & 36.3 & 35.9 & -0.0468 & 0.0376 & 0.0218 \\
\hline \multicolumn{12}{|c|}{ Omitted lines } \\
\hline 225 & -51.1 & 35.2 & 157.3 & 66.7 & 19.65 & -88 & 37 & 36.4 & $-9 E-4$ & -0.0046 & 0.0129 \\
\hline 250 & -51.1 & 35.2 & 157.1 & 67 & 19.72 & -88 & 37 & 36.4 & $-7.5 \mathrm{E}-4$ & -0.0042 & 0.0117 \\
\hline * & nao & kO & clo & BO & $k v$ & beta & gamma & $z$ & & & \\
\hline * & 140 & 5.8 & 116 & 48.2 & 1 & 0.039 & 1.5 & -2.47 & & & \\
\hline * & pna & $p k$ & $p c l$ & inc & $i k c$ & inkcc & $A / V$ & $h p$ & & & \\
\hline * & 0.00317 & 0.023 & 0.00354 & $3 E-5$ & 0 & 0 & 50.72 & 250 & & & \\
\hline * & Fluxes & PUMP & NetCh & NetNC & NetKC & NetNKCC & InCh & $\operatorname{InNC}$ & $\operatorname{In} K C$ & $\operatorname{InNKCC}$ & \\
\hline$*$ & $\mathrm{Na}$ & -1.372 & 0.9592 & 0.4165 & 0 & 0 & 0.9962 & 0.487 & 0 & 0 & \\
\hline$*$ & $\mathrm{~K}$ & 0.9146 & -0.8979 & 0 & 0 & 0 & 0.2994 & 0 & 0 & 0 & \\
\hline * & $\mathrm{Cl}$ & 0 & -0.396 & 0.4165 & 0 & 0 & 0.136 & 0.487 & 0 & 0 & \\
\hline * & OSOR & 3.05 & & & & & & & & & \\
\hline
\end{tabular}

3. If in the process of computation the internal sodium concentration drops below 0.1 , a message "LOW SODIUM" appears, and the computation stops.

The executable file BEZ01.exe should be used on Win32 systems together with the file DATA.txt placed in the same directory. The results of computation appear in the file RES.txt. The executable file and DATA.txt file should be obtained by e-mail: verenino@gmail.com or via1938@mail.ru or v.yurinskaya@mail.ru.

Examples of using the executable file

Finding a balanced state of a system with arbitrary kinetic parameters. The program can be used to find intracellular concentrations $[\mathrm{Na}]_{\mathrm{i}},[\mathrm{K}]_{\mathrm{i}},[\mathrm{Cl}]_{\mathrm{i}}$, the MP and cell water content corresponding to balanced ion distribution, i.e. the state when the total influx of each ion species is equal to its efflux and the derivatives are zero (within specified limits). The kinetic parameters, initial intracellular ion concentrations and concentrations of ions and other osmolytes in the external solution are entered into the file DATA.txt (Table 2). One should 
Fig. 1. Dependence of cell ion balance on the ratios $p_{\mathrm{Na}} / \beta$ and $\gamma p_{\mathrm{K}} / \beta$ in the presence of various cotransporters. The data were obtained by using a procedure similar to that illustrated in Table 3 but with initial ion concentrations corresponding to $z=-1.30$; the external concentrations were $[\mathrm{Na}]_{0}=150 \mathrm{mM},[\mathrm{K}]_{0}=5 \mathrm{mM}$, $[\mathrm{Cl}]_{0}=155 \mathrm{mM}$. In the presence of cotransport, the curves were computed for the indicated values of kinetic parameters inc $/ \beta$, inkcc/ $\beta, i k c / \beta, p_{\mathrm{c}} / \beta$. The numbers by the curves in panels J, K, and $\mathrm{L}$ show the ratios (in \%) of cotransport influxes to the $\mathrm{Na}^{+}$pump efflux (for $\mathrm{NC}$ ) or to the $\mathrm{K}^{+}$pump influx (for NKCC, $\mathrm{KC)}$.

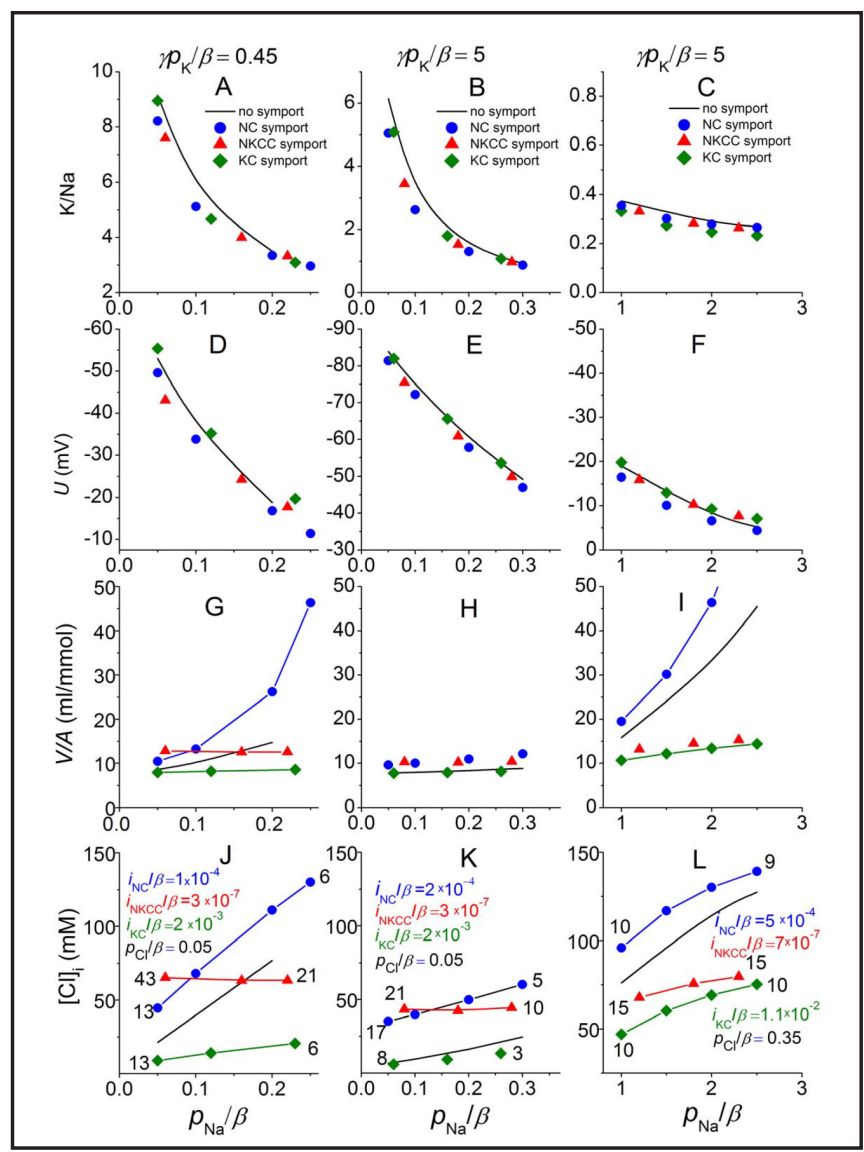

keep in mind that intracellular concentrations $[\mathrm{Na}]_{\mathrm{i}},[\mathrm{K}]_{\mathrm{i}},[\mathrm{Cl}]_{\mathrm{i}}$ and the total extracellular concentration of osmolytes determine $z$ (see Eq. 3). Therefore, the balanced states calculated for different initial $[\mathrm{Na}]_{i},[\mathrm{~K}]_{i},[\mathrm{Cl}]_{i}$ may be different even when the composition of the medium and all kinetic parameters are identical.

When running BEZ01.exe, the results appear after some delay in the file RES.txt (Table 3 ). To illustrate the process, we ran the program for unbalanced initial concentrations $[\mathrm{Na}]_{\mathrm{i}}=58 \mathrm{mM},[\mathrm{K}]_{\mathrm{i}}=136 \mathrm{mM},[\mathrm{Cl}]_{\mathrm{i}}=63 \mathrm{mM}$. The parameters were chosen such as to ensure the balanced concentrations similar to those in U937 cells. One can see that at $t=250 \mathrm{~min}$ the total $\mathrm{Cl}^{-}$influx/efflux ratio differs from unity by $5.2 \%(0.4165 / 0.3960=1.052)$. This corresponds to $\mathrm{prcl}=0.0117$. Practically, this means that a balanced distribution of $\mathrm{Cl}^{-}$is achieved at $4 \mathrm{~h}$. The distribution of $\mathrm{Na}^{+}$and $\mathrm{K}^{+}$at $250 \mathrm{~min}$ is even closer to the balanced state. The values prna, prk, and prcl in the last columns enable validation of the balance at each time moment.

Balanced state as a function of kinetic parameters. The executable file allows derivation of the dependence of balanced values of $[\mathrm{Na}]_{i},[\mathrm{~K}]_{\mathrm{i}},[\mathrm{Cl}]_{\mathrm{i}^{\prime}}, \mathrm{MP}$ and cell water content on kinetic parameters characterizing the pump, channels and cotransporters. Importantly, balanced concentrations are determined not by the absolute values of parameters but by their ratios. Indeed, if the left sides of Eqs. 6-8 are set to zero, the equalities remain true if divided by a constant. We prefer to relate the kinetic parameters to the pump rate constant $\beta$ because it can be obtained directly from the experiment. Only the rate of approaching the balanced state depends on the absolute values of kinetic parameters.

Fig. 1 shows how the $\mathrm{Na} / \mathrm{K}$ pump activity, $\mathrm{Na}^{+}, \mathrm{K}^{+}, \mathrm{Cl}^{-}$ion channel permeabilities, and the three major types of cotransport should affect ion and water balance and the MP. It can be seen that the type of cells (high-potassium - high MP, high-potassium - low MP or lowpotassium - low MP) is determined mainly by the two ratios, $\gamma p_{\mathrm{K}} / \beta$ and $p_{\mathrm{Na}} / \beta$. In the given examples, the combination of $\gamma p_{\mathrm{K}} / \beta=0.45$ and $p_{\mathrm{Na}} / \beta=0.05 \div 0.3$ will produce cells with 
Fig. 2. Effect of cotransporters on $[\mathrm{Cl}]_{i}$, cell water $(V / A)$ and $\Delta \mu_{\mathrm{Cl}}$ for various cell types and $p_{\mathrm{Cl}}$. NKCC - triangles, KC - diamonds, NC circles. The $\mathrm{X}$ axis units for cotransporters are shown at the bottom of the Figure. The data were computed as for Fig. 1.

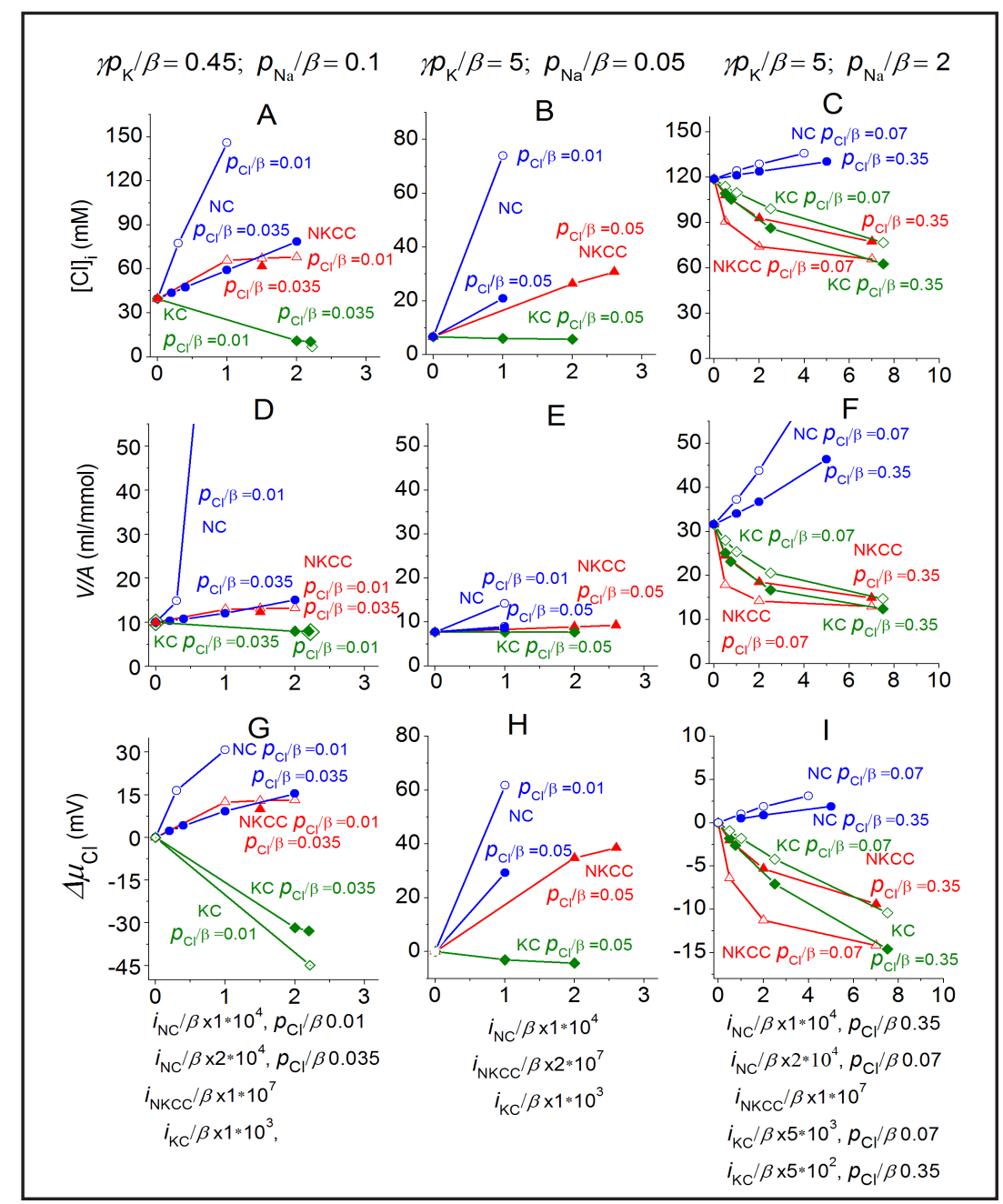

relatively high MP and high $\mathrm{K} / \mathrm{Na}$ ratios. If $\gamma p_{\mathrm{K}} / \beta$ is increased to 5 , the $\mathrm{K} / \mathrm{Na}$ will drop and the MP will increase further. Increasing the $p_{\mathrm{Na}} / \beta$ ratio while keeping $\gamma p_{\mathrm{K}} / \beta=5$ will yield low-potassium, low MP cells. Conversely, the values of $\mathrm{K} / \mathrm{Na}, U, V / A$ and $[\mathrm{Cl}]_{\mathrm{i}}$ determine the magnitude of $\gamma p_{\mathrm{K}} / \beta$ and $p_{\mathrm{Na}} / \beta$. This fact can be used to find the range of variation of these important parameters.

The effect of the contransporters is the strongest on $[\mathrm{Cl}]_{\mathrm{i}}$ and $V / A$, while the $\mathrm{K} / \mathrm{Na}$ ratio and MP are only slightly affected. Importantly, the effects of $p_{\mathrm{K}}, \beta$ and $p_{\mathrm{Na}}$ on $[\mathrm{Cl}]_{\mathrm{i}}$ and $V / A$ depend on whether cotransporters are present in the system. The NC cotransport enhances, and NKCC or KC cotransport reduces the effect. The relationships between cotransport fluxes and other fluxes are shown in Fig. 1J-1L. Under some circumstances, the NC cotransport can substantially affect cell ion and water even if its share in the overall flux is only $5-10 \%$. Such small fluxes can easily escape detection by inhibitors, and calculations would be the most effective way to study them.

Fig. 2 shows the dependence of $[\mathrm{Cl}]_{i}, V / A$ and $\Delta \mu_{\mathrm{Cl}}$ on cotransport rate coefficients under different $p_{\mathrm{Cl}}$. The effect of the NC cotransport is to increase $V / A,[\mathrm{Cl}]_{\mathrm{i}}$ and $\Delta \mu_{\mathrm{Cl}}$ (inside positive). Nonzero $\Delta \mu_{\mathrm{Cl}}$ at the balanced state means that there is a steady net flux through $\mathrm{Cl}^{-}$channels that depends on $p_{\mathrm{Cl}}$. Therefore the whole ion and water balance becomes dependent on $p_{\mathrm{Cl}}$. The KC transport has the opposite effect. The sign of NKCC-induced changes depends on the cell type.

The main conclusion is that the relationships in this multivariable system are quite complex, and a variety of outcomes are possible. The presented executable file enables one to estimate the effects of each species of transporters and channels, as well as their 
Fig. 3. Ion balance disturbance caused by turning off the pump at various $p_{\mathrm{Cl}}$. A model without cotransporters was used. The parameters were chosen as follows: na0 140, $k 0$ 5.8, cl0 116, B0 48.2, $k v 1$, na 52.6, $k 144.2$, cl 11.9, beta 0 (at the initial balanced value of 0.039), gamma 1.5, pna 0.006 , pk $0.06, p c l 0.1$ (triangles), or 0.001 (circles), or 0.0001 (solid lines), $h p$ 10000, inc $=i k c=i n k c c=0$.

combination, in every cell type and in every particular case.

\section{Inverse problem}

It is relatively straightforward to experimentally measure $[\mathrm{Na}]_{\mathrm{i}^{\prime}}[\mathrm{K}]_{\mathrm{i}},[\mathrm{Cl}]_{\mathrm{i}^{\prime}} \beta$ and the ratio of the ouabain-sensitive to ouabain-resistant $\mathrm{Rb}^{+}$influxes (OSOR) at the balanced state. The other question is how to calculate $p_{\mathrm{Na}} p_{\mathrm{K}^{\prime}} p_{\mathrm{CY}} i_{\mathrm{NC} C^{\prime}} i_{\mathrm{NKCC}} i_{\mathrm{KC}}$ from experimental data. This inverse problem is much harder than finding concentrations
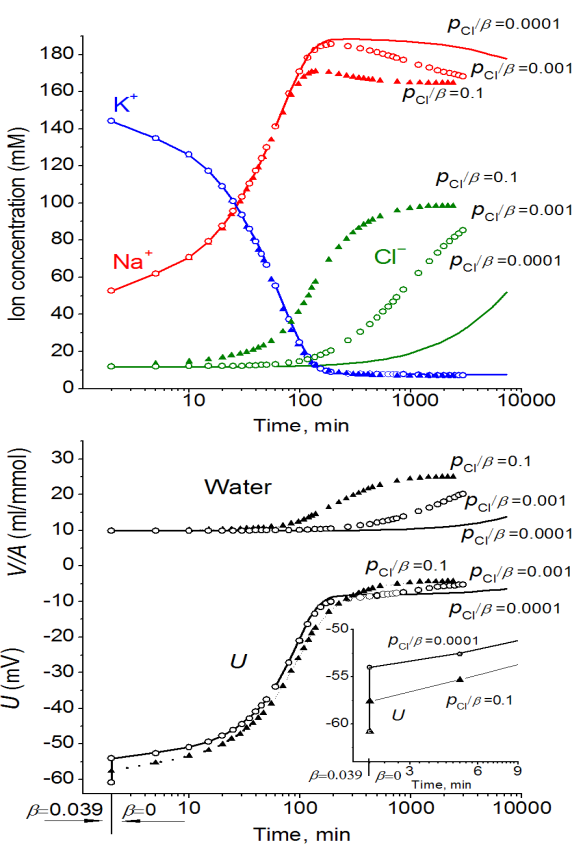

from known parameters, and we approach it by trial and error. In the case of U937 cells, [Na $]_{\mathrm{i}}$, $[\mathrm{K}]_{\mathrm{i}},[\mathrm{Cl}]_{\mathrm{i}}$, cell water content per unit of $A$, the pump coefficient $\beta$ and OSOR were measured as described previously [11-15]. These data proved sufficient to find a unique set of parameters corresponding to the balanced state for a model that includes the pump, $\mathrm{Na}^{+}, \mathrm{K}^{+}, \mathrm{Cl}^{-}$channels and a single type of cotransport. One can verify by using BEZ01.exe that different sets of $p_{\mathrm{N} a^{\prime}}$ $p_{\mathrm{K}^{\prime}} p_{\mathrm{C}{ }^{\prime}}$ and $i_{\mathrm{NC}}$ can yield the same $[\mathrm{Na}]_{\mathrm{i}^{\prime}}[\mathrm{K}]_{\mathrm{i}^{\prime}}[\mathrm{Cl}]_{\mathrm{i}}$, and the cell water content $V / A$ for a given $\beta$. However, the ratio OSOR in each case will be different. Because OSOR is easily determined in the experiment, a unique solution to the problem can be found.

When more than one type of cotransport is present, additional information is needed to arrive at a unique solution. Such information can be obtained, for example, by using cotransport blockers. In doing so, one needs to keep in mind that: (1) as we showed earlier, small fluxes that may easily escape detection by inhibitors can strongly influence the system; (2) many cells have significant one-to-one exchange with a zero net flux. This exchange seriously complicates the study of minor components by means of inhibitors. The analysis of flux balance using BEZ01.exe enables one to tell when a minor flux can be detected using inhibitors and when this would be impractical.

The reason that only the NC symport was assumed in modeling of U937 cells was that the transmembrane $\mathrm{Cl}^{-}$electrochemical potential difference in these cells $\left(\Delta \mu_{\mathrm{Cl}}\right.$ in Fig. 2 , mucl in Table 3) is internally positive, whereas KC would create a negative $\Delta \mu_{\mathrm{Cl}}$ (Fig. 2) and NKCC should be ineffective because of the nearly-zero sum mun+muk+mucl (Table 3). The parameters found in this way were taken as inherent for U937 cells in examples presented in Tables 1 and 2.

Errors in the determination of the parameters may result from errors in the measurement of cell ion and water content or may be due to the fact that the state that was assumed to be balanced was still in transition. Errors of the first type can be estimated by analysis of the relationships like those in Fig. 1 and 2 or by using BEZ01.exe. Errors of the second type will be discussed below.

\section{Dynamics of ion balance caused by blocking the pump: prediction and experiment}

It is well known that without the pump, a balanced ion distribution across the cell membrane cannot exist, and the cells would be swelling infinitely $[6,9,18]$. Nevertheless, real cells following pump inhibition by ouabain often do not swell for a long time. Low 
Fig. 4. Predicted and observed changes in U937 cells following pump inhibition with ouabain. (A) Time course of the changes in $[\mathrm{Na}]_{\mathrm{i}},[\mathrm{K}]_{\mathrm{i}}$, and $[\mathrm{Cl}]_{\mathrm{i}^{\circ}}$ Large symbols - experimental data (means $\pm \mathrm{SE}$, $\mathrm{n}=4$ ). Solid lines - data calculated for the following parameters: naO 140, k0 5.8, cl0 116, B0 48.2, kv 1, na $35, k 156$, cl 70, beta 0 , pna 0.00317, pk 0.023, pcl 0.00354, inc $3 \mathrm{E}-5, i k c=$ inkcc $=0, h p 400$, (before blocking the pump beta was 0.039), OSOR 3.06, gamma 1.5. Small symbols - data calculated for parameters: na 37.4, $k$ 156.3, cl 63.7, pna 0.00367, pk 0.0247, pcl 0.0035, inc 2.6E-5. (B) Time course of the changes in MP $(-U$, $\mathrm{mV})$ and cell water content $(V / A$, $\mathrm{ml} / \mathrm{mmol}$ ) calculated for the same conditions as for solid lines in (A). Initial levels are shown by the dashed line. (C) Time course of
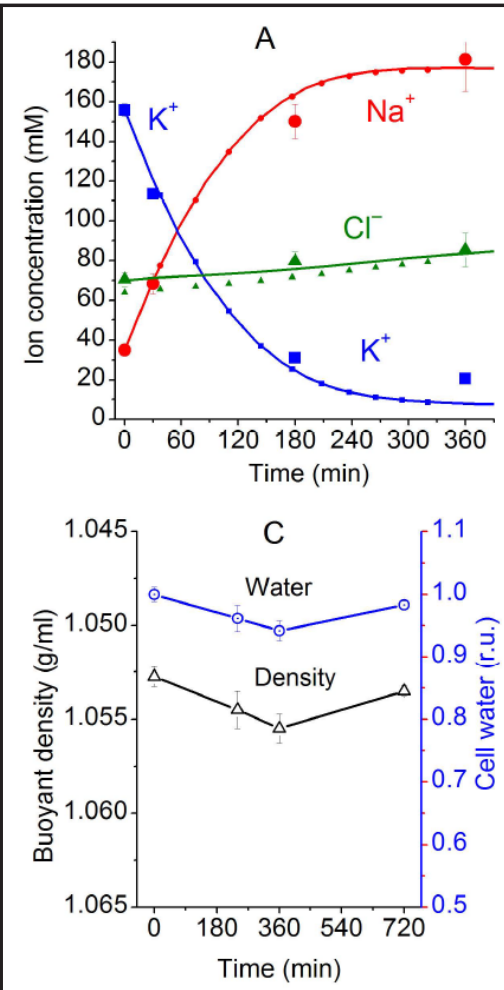

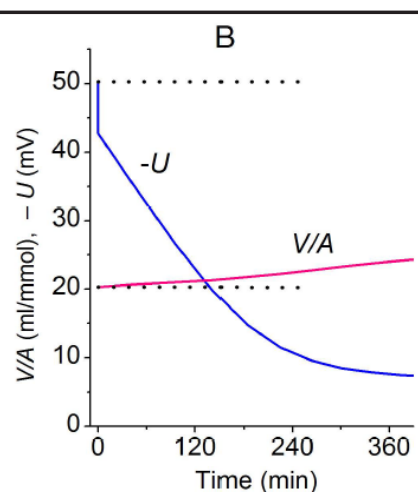

$\mathrm{D}$

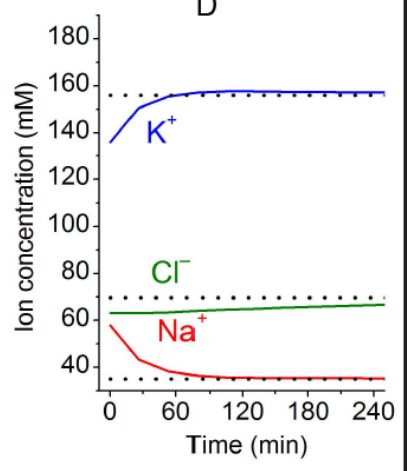

changes in cell buoyant density $\left(\mathrm{g} \cdot \mathrm{ml}^{-1}\right.$ ) and cell water content (relative units, means $\pm \mathrm{SE}, \mathrm{n}=8,2,3,3$ for $\mathrm{t}=0,240,360,720 \mathrm{~min}$, respectively). Cell water was calculated by density as described $[13,16]$. (D) Changes in $[\mathrm{Na}]_{\mathrm{i}},[\mathrm{K}]_{\mathrm{i}}$, and $[\mathrm{Cl}]_{\mathrm{i}}$ in the vicinity of the balanced state starting from na0 140, k0 5.8, cl0 116, B0 48.2, $\mathrm{kV}$ 1, na 58, $k 136, c l 63$ and calculated for the parameters: beta 0.039 , pna $0.00317, p k 0.023, p c l 0.00354$, inc $3 \mathrm{E}-5, i k c=$ inkcc $=0$.

permeability of $\mathrm{Cl}^{-}$channels as well as the involvement of the Ca-ATPase pump, Na-Ca antiporter and NKCC cotransport have been listed as possible reasons for the delay in swelling [19-21]. Fig. 3 illustrates the development of a disturbance caused by stopping the pump in the simplest cell model with $\mathrm{Na}^{+}, \mathrm{K}^{+}$and $\mathrm{Cl}^{-}$channels and no symports. One can see that substantial water accumulation starts only when the $\mathrm{K}^{+} / \mathrm{Na}^{+}$inversion is almost complete. Thus, the simple model, which only assumes low permeability for $\mathrm{Cl}^{-}$, is sufficient to explain the slow swelling caused by ouabain. No significant changes in the rate of $\mathrm{K}^{+}-\mathrm{Na}^{+}$ redistribution occur when $p_{\mathrm{Cl}}$ is varied by as much as three orders of magnitude, and only water and $\mathrm{Cl}^{-}$dynamics are affected. It should be noted that the prompt shift in the MP due to pump blocking, i.e. the "electrogenic" effect of the pump, is sensitive to $p_{\mathrm{Cl}}$ (see insert in Fig. 3). This is because the contribution of the pump to the total transmembrane current depends on all ion channels, including those for $\mathrm{Cl}^{-}$.

Fig. 4A-4C compares the observed and predicted time courses of ion and water changes caused by ouabain. The parameters used for calculations were derived from the analysis of the balanced state of untreated U937 cells. One could expect that the real properties of the ion transport machinery might change during a transition accompanied by such large variations in intracellular $\mathrm{Na}^{+}$and $\mathrm{K}^{+}$and in the MP. Nevertheless, the simplest model developed for the balanced state turned out to be quite effective in quantitative prediction of the complex interplay of ion fluxes after pump inhibition. This strongly implies that the rate coefficients for ion transfer via channels and $\mathrm{NC}$ cotransport, as well as the intracellular content of impermeant osmolytes $A$ and their charge $z$, remained stable during the transition. This indicates also that the flux equations used in the model are right. 
The question may arise as to the magnitude of an error in calculating the dynamics of transition if the parameters were based on an incompletely balanced state, e.g. after equilibration of cells for $1 \mathrm{~h}$ instead of $4 \mathrm{~h}$. Fig. $4 \mathrm{D}$ shows the changes in $[\mathrm{Na}]_{\mathrm{i}^{\prime}}[\mathrm{K}]_{\mathrm{i}}$ and $[\mathrm{Cl}]_{\mathrm{i}}$ in the vicinity of the balanced state. Only $[\mathrm{Cl}]_{\mathrm{i}}$ changes more or less appreciably (from 63.7 to $66.8 \mathrm{mM}$ ) between 1 and $4 \mathrm{~h}$. The kinetics of transition calculated using parameters based on an incomplete one-hour equilibration is shown in Fig. 4A by small symbols. Evidently, the introduced inaccuracy did not lead to significant errors. Thus, we conclude that the agreement between the observed and predicted dynamics is sufficiently good and holds in spite of possible errors in the parameters.

\section{Discussion}

Monovalent ions, cell volume and MP form a self-contained physiological "circuit". The ability to analyze and predict its behavior is essential for understanding the action of membrane-active drugs, apoptotic vs. oncotic cell death or for calibration of intracellular ion measurements. Unfortunately, all too often the complexity of the system makes it tempting to bypass the rigorous analysis, resulting in hasty and erroneous conclusions.

The main result of the present study is the executable file for calculation and analysis of monovalent ion fluxes across the plasma membrane mediated by the $\mathrm{Na} / \mathrm{K}$ pump, ion channels, and the three types of cotransporters for any type of animal cell. Fluxes of $\mathrm{Na}^{+}$, $\mathrm{K}^{+}$, and $\mathrm{Cl}^{-}$across the plasma membrane in a whole cell are highly interdependent first and foremost due to the conditions of macroscopic electroneutrality and osmotic balance. These are all well-established principles that are automatically satisfied by our model, enabling one to focus on specific changes in channels and transporters and on the effects of various conditions. Each ion pathway is characterized by a single parameter - the proportionality coefficient between the driving force and the ion flux via that particular pathway. For the driving force we used the traditional definition as the electrochemical potential difference for a single ion in case of its moving through the electroconductive channels and the sum of the electrochemical potential differences in case of the coupled ion transfer via co- and counter-transporters. To simplify the model, subtle dependencies of the rate coefficients on concentrations of other ions, as well as on the MP and other factors, were neglected. The $\mathrm{Na}^{+}$ and $\mathrm{K}^{+}$fluxes mediated by the pump were expressed as a linear function of intracellular $\mathrm{Na}^{+}$ concentration with a fixed $\mathrm{Na} / \mathrm{K}$ flux ratio of 1.5 [1]. These simplifications made the model more general and easier to use.

The reported data illustrate several of important general principles. First, the cell type (high-potassium with high MP, high-potassium or low-potassium, with low MP) is determined primarily by the two ratios, $\gamma p_{\mathrm{K}} / \beta$ and $p_{\mathrm{Na}} / \beta$. Importantly, the balanced state depends not on the absolute values of the coefficients but on their ratios. The pump rate coefficient would be most appropriate as a reference because it can be obtained directly by measuring the intracellular $\mathrm{Na}^{+}$and ouabain-sensitive $\mathrm{Rb}^{+}$or $\mathrm{K}^{+}$influxes. Only the rate of approaching the balanced state depends on the absolute values of kinetic parameters. Second, the cotransporters NC, NKCC and KC should strongly affect the intracellular chloride and water content but to a much lesser extent the cell K/Na ratio and MP. Their effects would vary significantly with the cell type and other conditions and depend on the permeability of $\mathrm{Cl}^{-}$channels, i.e. on $p_{\mathrm{Cl}}$. The most one can say is that the NC cotransport tends to increase intracellular chloride and water content, whereas NKCC, and to a certain extent, $\mathrm{KC}$ cotransport stabilize water balance against changes in the $\mathrm{Na} / \mathrm{K}$ pump and channels. Under some circumstances, the NC cotransport can substantially affect cell ion and water balance even if its share in the overall flux is only 5-10\%. Such small fluxes can easily escape detection by inhibitors, and calculations would be the most effective way to study them.

The presented approach was applied to analyzing the time course of ion and water disturbance in U937 cells caused by stopping the sodium pump with ouabain. It turned out, rather unexpectedly, that using the parameters found for the balanced state gave a near- 
perfect match between the observed and calculated time courses. One should remember that our mathematical model, as well as those by all previous authors, is based on the assumptions that: (1) monovalent ion fluxes are determined by their concentration gradients and MP according to the indicated original equations; (2) the intracellular content of impermeant osmolytes and their average charge remain constant during transient process; (3) all the kinetic parameters remain constant. Thus, three different types of causes could lead to discrepancy between prediction and reality. Data obtained on U937 cells showed that in the considered case the original flux equations were adequate and changes in the kinetic parameters, as well as in the intracellular content of impermeant osmolytes and their charge, were insignificant in spite of inversion of the intracellular $\mathrm{K}^{+} / \mathrm{Na}^{+}$ratio and a large decrease in MP. We believe that computational modeling using our executable file could be a promising tool for revealing possible changes in the machinery regulating MP and monovalent ion gradients.

\section{Acknowledgements}

This study was supported by the Program of the Presidium of the Russian Academy of Sciences, project "Coordination of monovalent ion fluxes in regulation of ion and water balance in animal cells", registration no. 01201267208, and Russian Foundation for Basic Research, project no. 12-04-01669a. IAV, VEY, AAV. The authors acknowledge the meticulous preparation of the manuscript by Lejla Subasic.

\section{References}

1 Jakobsson E: Interactions of cell volume, membrane potential, and membrane transport parameters. Am J Physiol Cell Physiol 1980;238:C196-C206.

-2 Lew VL, Bookchin RM: Volume, pH, and ion-content regulation in human red cells: analysis of transient behavior with an integrated model. J Membr Biol 1986;92:57-74.

-3 Lew VL, Freeman CJ, Ortiz OE, Bookchin RM: A mathematical model of the volume, pH, and ion content regulation in reticulocytes. Application to the pathophysiology of sickle cell dehydration. J Clin Invest 1991;87:100-112.

4 Hernández JA, Cristina E: Modeling cell volume regulation in nonexcitable cells: the roles of the $\mathrm{Na}^{+}$pump and of cotransport systems. Am J Physiol 1998;275:C1067-C1080.

5 Hernández JA, Chifflet S: Electrogenic properties of the sodium pump in a dynamic model of membrane transport. J Membr Biol 2000;176:41-52.

6 Armstrong CM: The Na/K pump, $\mathrm{Cl}$ ion, and osmotic stabilization of cells. Proc Natl Acad Sci USA 2003;100:6257-6262.

7 Terashima K, Takeuchi A, Sarai N, Matsuoka S, Shim EB, Leem CH, Noma A: Modelling Cl homeostasis and volume regulation of the cardiac cell. Philos Trans A Math Phys Eng Sci 2006;364:1245-1265.

8 Fraser JA, Huang CL: A quantitative analysis of cell volume and resting potential determination and regulation in excitable cells. J Physiol 2004;559:459-478.

-9 Fraser JA, Huang CL: Quantitative techniques for steady-state calculation and dynamic integrated modelling of membrane potential and intracellular ion concentrations. Prog Biophys Mol Biol 2007;94:336-372.

10 Mauritz JM, Esposito A, Ginsburg H, Kaminski CF, Tiffert T, Lew VL: The homeostasis of Plasmodium falciparum-infected red blood cells. PLoS Comput Biol 2009;5:e1000339.

-11 Yurinskaya V, Goryachaya T, Guzhova I, Moshkov A, Rozanov Y, Sakuta G, Shirokova A, Shumilina E, Vassilieva I, Lang F, Vereninov A: Potassium and sodium balance in U937 cells during apoptosis with and without cell shrinkage. Cell Physiol Biochem 2005;16:155-162.

12 Vereninov AA, Goryachaya TS, Moshkov AV, Vassilieva IO, Yurinskaya VE, Lang F, Rubashkin AA: Analysis of the monovalent ion fluxes in U937 cells under the balanced ion distribution: recognition of ion transporters responsible for changes in cell ion and water balance during apoptosis. Cell Biol Int 2007;31:382-393. 
13 Vereninov AA, Rubashkin AA, Goryachaya TS, Moshkov AV, Rozanov YM, Shirokova AV, Strelkova EG, Lang F, Yurinskaya VE: Pump and channel $\mathrm{K}^{+}\left(\mathrm{Rb}^{+}\right)$fluxes in apoptosis of human lymphoid cell line U937. Cell Physiol Biochem 2008;22:187-194.

14 Yurinskaya VE, Rubashkin AA, Vereninov AA: Balance of unidirectional monovalent ion fluxes in cells undergoing apoptosis: why does $\mathrm{Na}^{+} / \mathrm{K}^{+}$pump suppression not cause cell swelling? J Physiol 2011;589:2197-2211.

-15 Yurinskaya VE, Moshkov AV, Rozanov YM, Shirokova AV, Vassilieva IO, Shumilina EV, Lang F, Volgareva EV, Vereninov AA: Thymocyte $\mathrm{K}^{+}, \mathrm{Na}^{+}$and water balance during dexamethasone- and etoposide-induced apoptosis. Cell Physiol Biochem 2005;16:15-22.

16 Vereninov IA., Vereninov AA.: Algoritmy komp'iuternogo modelirovaniia perenosa ionov v kletkakh [Algorithms of computer modelling of ion interaction in cells] (rus). St Petersburg State Polytechnical University Journal Computer Science Telecommunication and Control System 2013;169:91-97.

17 Forsythe GE, Malcolm MA, Moler CB: Computer Methods for Mathematical Computations. Englewood Cliffs, N.J. Prentice-Hall, 1977.

18 Hoffmann EK: Volume regulation in cultured cells; in Kleinzeller A (ed): Cell volume control: fundamental and comparative aspects in animal cells. New York, Academic press, 1987, pp 125-180.

19 Lang F, Busch GL, Ritter M, Völkl H, Waldegger S, Gulbins E, Häussinger D: Functional significance of cell volume regulatory mechanisms. Physiol Rev 1998;78:247-306.

20 Takeuchi A, Tatsumi S, Sarai N, Terashima K, Matsuoka S, Noma A: Ionic mechanisms of cardiac cell swelling induced by blocking $\mathrm{Na}^{+} / \mathrm{K}^{+}$pump as revealed by experiments and simulation. J Gen Physiol 2006;128:495507.

21 Dierkes PW, Wüsten HJ, Klees G, Müller A, Hochstrate P: Ionic mechanism of ouabain-induced swelling of leech Retzius neurons. Pflügers Arch 2006;452:25-35. 